\title{
EFEITO DO CONDICIONAMENTO NA PRODUÇÃO DE MUDAS DE Acacia mangium Willd. E NO ARMAZENAMENTO DAS SEMENTES
}

\author{
Sue Éllen Ester Queiroz ${ }^{1}$, Jordana Alves da Silva Branquinho ${ }^{2}$, Alana Vaz Silva ${ }^{2}$ \\ Paulo Henrique Sales Guimarães ${ }^{3}$ \\ ${ }^{1}$ Professora do Departamento de Biologia - Instituto Federal do Sul de Minas - Campus \\ Machado - sue.queiroz@ifsuldeminas.edu.br \\ ${ }^{2}$ Tecnóloga em Gestão Ambiental pelo Instituto Federal Goiano. \\ ${ }^{3}$ Professor do departamento de Estatística - Universidade Federal de Lavras
}

Recebido em: 06/04/2018 - Aprovado em: 10/06/2018 - Publicado em: 20/06/2018

DOI: 10.18677/EnciBio_2018A137

\begin{abstract}
RESUMO
As sementes de Acacia mangium Willd. possuem dormência, sem tratamento prégerminativo a germinação é lenta e desuniforme, sendo assim a aplicação de técnicas para acelerar e uniformizar a germinação torna-se essencial para a produção de mudas. Assim, teve-se como objetivo avaliar o efeito do condicionamento na germinação, na produção de mudas e no armazenamento das sementes. Para avaliar o efeito do condicionamento na germinação, avaliou-se quatro potenciais hídricos $(0,0 ;-0,1 ;-0,2 ;-04 \mathrm{MPa})$, três temperaturas $(15 ; 20$; e $25^{\circ} \mathrm{C}$ ) e três tempos de embebição (28; 36; e 44 horas), totalizando 36 tratamentos. Para avaliar o efeito do condicionamento na produção de mudas utilizou-se dois tratamentos: sementes com condicionamento $\left(-0,4 \mathrm{MPa}\right.$ a $15^{\circ} \mathrm{C}$ por 28 horas) e sem condicionamento. Para verificar o efeito do condicionamento no armazenamento das sementes foram avaliadas sementes com e sem condicionamento, armazenadas em temperatura de 10 e $25^{\circ} \mathrm{C}$, em saco plástico e pote de vidro. Observou-se que o potencial $-0,4 \mathrm{MPa}$ na temperatura de $15^{\circ} \mathrm{C}$ por 28 horas demonstrou ser o mais eficiente sobre as variáveis germinação e IVG em laboratório. Na produção de mudas, o condicionamento não interferiu na germinação, sobrevivência e parâmetros morfológicos. O condicionamento limitou o período de armazenamento das sementes, podendo ser armazenadas até os 60 dias, as sementes armazenadas durante 150 dias tiveram a germinação e IVG reduzidos. Assim, pode-se concluir que o condicionamento influencia no desempenho germinativo das sementes de $A$. mangium em laboratório. Sendo que o condicionamento seguido de armazenamento é considerado viável até os 60 dias de armazenamento.
\end{abstract}

PALAVRAS-CHAVE: dormência, germinação, osmocondicionamento.

\section{EFFECT OF CONDITIONING ON THE PRODUCTION OF MUDAS Acacia mangium Willd. AND ON SEED ARMING}

\begin{abstract}
Seeds of Acacia mangium Willd. they have dormancy, without pre-germinative treatment the germination is slow and uneven, and thus the application of techniques to accelerate and standardize the germination becomes essential for the production
\end{abstract} ENCICLOPÉDIA BIOSFERA, Centro Científico Conhecer - Goiânia, v.15 n.27; p. 947 2018 
of seedlings. Thus, the objective was to evaluate the effect of germination conditioning, seedling production and seed storage. To evaluate the effect of conditioning on germination, four water potentials $(0.0 ;-0.1 ;-0.2 ;-04 \mathrm{MPa})$, three temperatures $\left(15,20\right.$, and $25^{\circ} \mathrm{C}$ ) and three times (28, 36 and 44 hours), totaling 36 treatments. To evaluate the effect of conditioning on the production of seedlings, two treatments were used: seeds with conditioning (-0.4 MPa at $15^{\circ} \mathrm{C}$ for 28 hours) and without conditioning. In order to verify the effect of the conditioning in the seed storage, seeds with and without conditioning, stored at a temperature of 10 and $25^{\circ}$ $\mathrm{C}$, in plastic bag and glass pot were evaluated. It was observed that the potential -0.4 $\mathrm{MPa}$ at the temperature of $15^{\circ} \mathrm{C}$ for 28 hours proved to be the most efficient on the variables germination and IVG in the laboratory. In the production of seedlings, the conditioning did not interfere in the germination, survival and morphological parameters. The conditioning limited the storage period of the seeds and could be stored up to 60 days, the seeds stored for 150 days had the germination and IVG reduced. Thus, it can be concluded that the conditioning influences the germination performance of $A$. mangium seeds in the laboratory. Being that the conditioning followed of storage is considered viable until the 60 days of storage.

KEYWORDS: dormancy, germination, priming.

\section{INTRODUÇÃO}

As sementes, quando utilizadas para a produção de mudas, devem apresentar características como alta porcentagem de germinação, sincronia e rapidez no desenvolvimento para que a produção de mudas seja economicamente viável. Porém, algumas espécies apresentam retardamento e desuniformidade na germinação, mesmo sob condições ótimas de umidade, luz, temperatura e oxigênio. Isso decorre devido a dormência das sementes.

As sementes de $A$. mangium apresentam dormência devido a impermeabilidade do tegumento à água. Esta característica inerente à espécie representa uma dificuldade na produção de mudas para plantios comerciais, visto que a propagação da espécie ocorre principalmente de forma sexuada (SMIDERLE et al., 2005). Sendo assim, o papel da tecnologia de sementes é adaptar ou criar métodos tecnológicos adequados para melhoria no padrão de qualidade das sementes, especialmente quando se trata de atividade de produção de mudas com objetivo de obtenção de estande uniforme (GUEDES et al., 2013).

$\mathrm{Na}$ tentativa de diminuir o período entre a semeadura e a emergência de plântulas, existem diferentes tratamentos pré-semeadura, os quais vêm sendo estudados para diversas espécies, entre eles, o condicionamento osmótico (Morais et., 2014). Além disto, o condicionamento de sementes tem contribuído para melhorar o desempenho e resistência de plântulas aos estresses edafo-climáticos (MASETTO et al., 2013).

Esta técnica baseia-se na iniciação do metabolismo da germinação por meio da hidratação controlada das sementes, em que vários processos metabólicos são ativados, mas sem permitir a protrusão da radícula. Após a hidratação as sementes são lentamente desidratadas até atingir o grau de umidade original. Isso possibilita o manuseio ou o armazenamento das sementes, além de permitir que as sementes sejam comercializadas sem dormência (POWEL et al., 2000).

O condicionamento das sementes pode ser realizado a partir da embebição das sementes em soluções de baixo potencial hídrico, com o uso de agentes osmóticos, como polietileno glicol, o que é denominado de condicionamento 
osmótico. Outra forma de realizar o condicionamento das sementes se dá utilizandose somente água no controle da embebição. Este processo é chamado de hidrocondicionamento (MASETTO et al., 2013).

Os efeitos benéficos dos diferentes tratamentos de condicionamento sobre $o$ aumento no desempenho germinativo e seus efeitos sobre o armazenamento das sementes de diferentes espécies são bem documentados na literatura. Entretanto, poucos trabalhos abordam a eficiência da técnica no desempenho posterior das plântulas, em condições de campo (MASETTO et al., 2013). Estudos sobre a aplicação da técnica de condicionamento em sementes de $A$. mangium, visando à uniformidade de germinação e estabelecimento de plântulas não constam na literatura e são importantes para subsidiar sua propagação em programas de produção de mudas. Nesse sentido, objetivou-se com este estudo avaliar o efeito do condicionamento das sementes na produção de mudas $A$. mangium e avaliar o efeito do condicionamento no armazenamento das sementes.

\section{MATERIAL E MÉTODOS}

As sementes de $A$. mangium foram obtidas a partir de um povoamento puro de 600 árvores-matriz com dez anos de idade, localizado na cidade de Viçosa-MG. O experimento foi conduzido entre os anos de 2013 e 2014, nas dependências do Instituto Federal Goiano, campus Urutaí, Goiás, sob as coordenadas geográficas

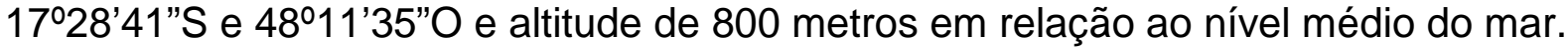
O trabalho foi composto por 3 etapas, sendo a etapa 1 a verificação do efeito do condicionamento na qualidade fisiológica da semente; etapa 2 avaliação do efeito do condicionamento na produção de mudas; e etapa 3 efeito do condicionamento no armazenamento das sementes

\section{Efeito do condicionamento na qualidade fisiológica da semente}

Para avaliar o efeito do condicionamento na qualidade fisiológica da semente utilizou-se 0 delineamento estatístico inteiramente casualizado em esquema fatorial triplo com quatro potenciais hídricos $(0,0 ;-0,1 ;-0,2 ;-04 \mathrm{MPa})$, três temperaturas $\left(15 ; 20\right.$; e $\left.25^{\circ} \mathrm{C}\right)$ e três tempos de embebição (28; 36; e 44 horas), totalizando 36 tratamentos.

O teste de germinação foi realizado utilizando quatro repetições contendo 25 sementes cada uma. As sementes foram previamente esterilizadas com uma solução de hipoclorito de sódio a $1 \%$ de concentração, durante 10 minutos e em seguida lavadas em água corrente. As sementes foram colocadas para embeber em água destilada entre folhas de papel de germinação, em placas de Petri de $90 \mathrm{~mm}$ de diâmetro. As placas de Petri foram acondicionadas em BOD reguladas em luz e temperatura constante de $25^{\circ} \mathrm{C}$. As sementes foram consideradas germinadas quando houve a protrusão da radícula $(1 \mathrm{~mm})$.

Para a determinação da curva de embebição, utilizada para determinar os tempos de embebição utilizados como tratamento, as sementes passaram por escarificação química, por meio de imersão em ácido sulfúrico durante 60 minutos, para superação da dormência. Utilizam-se 10 repetições com uma semente cada, dispostas entre folhas de papel de germinação com água destilada, em placas de Petri de $90 \mathrm{~mm}$ de diâmetro, na temperatura $25^{\circ} \mathrm{C}$. As sementes foram pesadas diariamente em balança digital e precisão $0,01 \mathrm{~g}$ a cada 4 horas durante o período de quatro dias, até o início da protrusão da radícula.

A partir da curva de embebição das sementes de A. mangium, observa-se 
que a fase de repouso ocorreu no intervalo de 28 a 44 horas de embebição (Figura 1 ), sendo assim os intervalos de tempo para o condicionamento estabelecido foram 28,36 e 44 horas.

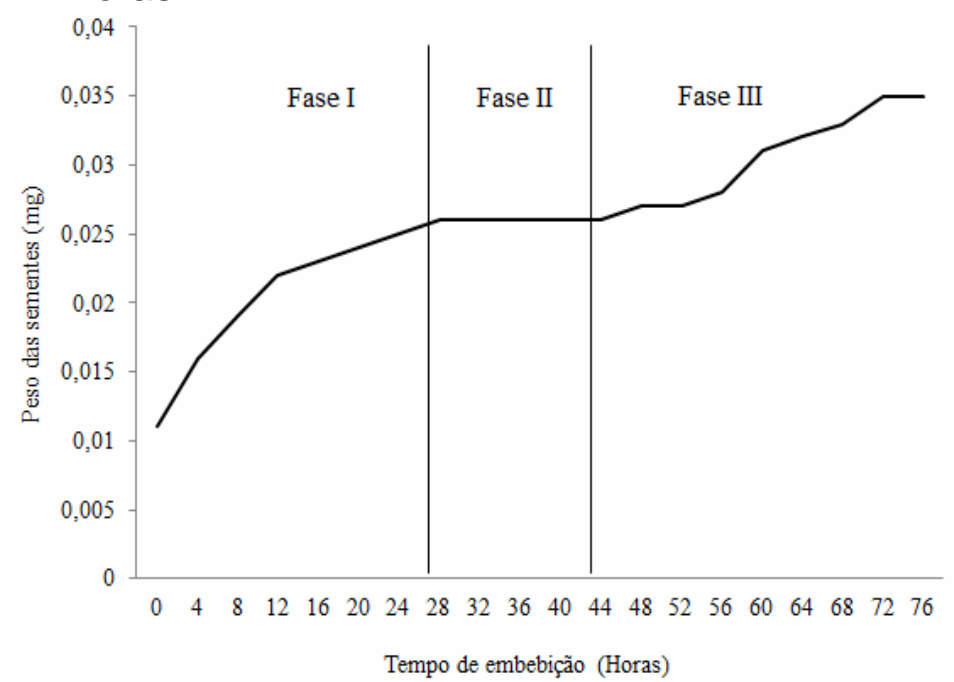

FIGURA 1. Curva de embebição das sementes de $A$. mangium Willd. com as três fases da germinação. Urutaí, Goiás, 2014. Fonte: autores

Para o condicionamento osmótico, inicialmente fez-se a escarificação química das sementes distribuídas em placas de Petri de $90 \mathrm{~mm}$ de diâmetro, contendo duas folhas de papel de germinação, umedecidas com $10 \mathrm{ml}$ de solução PEG 6000, em concentrações capazes de desenvolver potenciais hídricos de 0,0 (água pura), -0,1 -0,2 e -0,4 (MPa), em três tempos de embebição (28, 36, 44 horas - determinados de acordo com a curva de embebição) e em três temperaturas (15, 20 e $25^{\circ} \mathrm{C}$ ), totalizando 36 tratamentos. Os potenciais hídricos das soluções de PEG foram preparados de acordo com a fórmula de Michel e Kaufman (1973). As placas foram acondicionadas em câmaras de germinação, nas temperaturas de $15^{\circ}, 20^{\circ} \mathrm{e}$ $25^{\circ} \mathrm{C}$.

Para que as sementes pudessem permanecer expostas a níveis constantes dos potencias osmóticos das soluções durante o experimento, foram transferidas a cada três dias para outras placas de petri forradas com papel germinação recémumedecido, nas respectivas soluções testes. Após completarem cada período de condicionamento, as sementes foram retiradas do condicionamento e lavadas em água corrente. Em seguida, uma amostra foi tomada para a determinação da porcentagem de umidade em que as sementes se encontraram no final de cada tempo de embebição. Para a secagem, as sementes foram acondicionadas em câmara de germinação tipo BOD, à temperatura de $20^{\circ} \mathrm{C}$, dentro de caixas tipo gerbox, com uma tela de alumínio, sobre a qual foram dispostas as sementes após a adição de solução saturada de cloreto de magnésio ( $30 \%$ UR), ao fundo de cada gerbox. As caixas foram seladas e mantidas na câmara por 17 horas, até as sementes atingirem o grau de umidade anterior à embebição.

Para a análise da qualidade fisiológica primeiramente, as sementes foram mantidas em câmara úmida para retardar a taxa de absorção inicial de água, evitando-se, assim, possíveis danos por rápida embebição. A câmara úmida foi montada com uso de caixas tipo gerbox, com uma tela de alumínio e sobre esta foram dispostas as sementes, após a adição de $20 \mathrm{~mL}$ de água ao fundo de cada gerbox. As caixas foram seladas e mantidas em BOD à $25^{\circ} \mathrm{C}$, por 48 horas. ENCICLOPÉDIA BIOSFERA, Centro Científico Conhecer - Goiânia, v.15 n.27; p. 950 2018 
Posteriormente as sementes foram colocadas para embeber, entre folhas de papel de germinação, em placas de Petri de $90 \mathrm{~mm}$ de diâmetro, umedecidas com água destilada, até a saturação do papel, em temperatura de $25{ }^{\circ} \mathrm{C}$. Os experimentos de germinação foram monitorados diariamente, considerando-se semente germinada aquela cuja raiz primária atingiu $1 \mathrm{~mm}$ de comprimento. A germinação foi avaliada por meio da porcentagem final de germinação e o vigor, pelo índice de velocidade de germinação (IVG), de acordo com a fórmula:

$$
\mathrm{IVG}=(\mathrm{G} 1+\mathrm{G} 2+\cdots+\mathrm{Gn}) /(\mathrm{N} 1+\mathrm{N} 2+\cdots+\mathrm{Nn})
$$

em que:

$\mathrm{G} 1, \mathrm{G} 2, \ldots \mathrm{Gn}$ = número de sementes com radículas emergidas, computadas na primeira contagem, segunda contagem, $\ldots$, última contagem.

$\mathrm{N} 1, \mathrm{~N} 2, \ldots \mathrm{Nn}=$ número de dias de semeadura à primeira, segunda,.., última contagem.

\section{Efeito do condicionamento na produção de mudas}

Para avaliar o efeito do condicionamento sobre o desenvolvimento das mudas de $A$. mangium, foi instalado um experimento no viveiro do Instituto Federal Goiano - Campus Urutaí, no município de Urutaí - GO, entre os meses de fevereiro a junho de 2014, por um período de 135 dias. O clima da área, conforme classificação de Köppen é do tipo Cwb, caracterizado como tropical de altitude, com inverno seco e verão quente e chuvoso. Os dados de precipitação pluviométrica e de temperatura são apresentados na Figura 2.

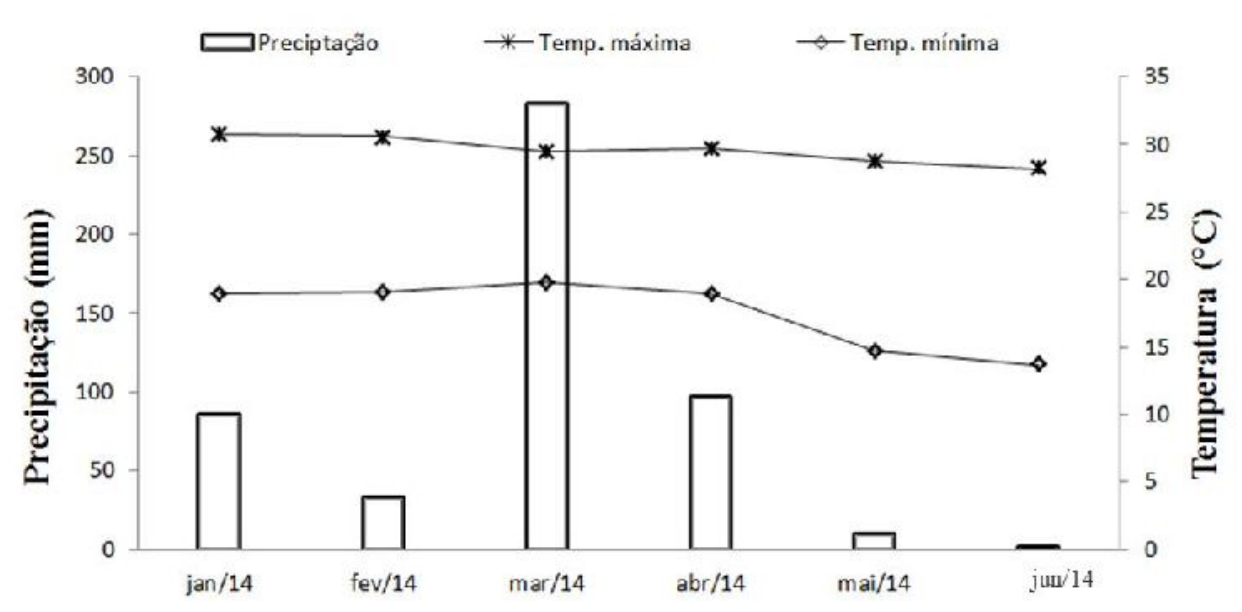

FIGURA 2. Precipitação total mensal e médias mensais de temperaturas, máximas e mínimas, no período de janeiro a junho de 2014. Fonte: Instituto Nacional de Meteorologia - INMET/Ipameri, Goiás (2015).

$O$ delineamento experimental adotado foi o delineamento inteiramente casualizado com trinta repetições. O experimento foi constituído de dois tratamentos: sementes com condicionamento $\left(-0,4 \mathrm{MPa}\right.$ a $15^{\circ} \mathrm{C}$ por 28 horas) e sem condicionamento. 
A semeadura foi feita diretamente em sacos plásticos de capacidade de 2 $\mathrm{dm}^{3}$, contendo substrato (Tabela 1) preparado a partir de $50 \%$ de terra de subsolo (Latossolo Vermelho Distrófico típico), 25\% de areia, 25\% de húmus de minhoca e $400 \mathrm{mg} / \mathrm{dm}^{3}$ de superfosfato simples.

TABELA 1. Características químicas do substrato utilizado na produção de mudas de $A$. mangium.

\begin{tabular}{|c|c|c|c|c|c|c|c|c|}
\hline$\underset{\mathrm{H}_{2} \mathrm{O}}{\mathrm{pH}}$ & $P$ & $\mathrm{~K}$ & $\mathrm{Al}^{3+}$ & $\mathrm{H}^{+} \mathrm{AL}$ & $\mathrm{Ca}^{2+}+\mathrm{Mg}^{2+}$ & CTC & $\mathrm{M}$ & V \\
\hline & \multicolumn{2}{|c|}{$\mathrm{mg} \mathrm{dm}^{-3}$} & \multicolumn{4}{|c|}{$\mathrm{Cmol}_{\mathrm{C}} \mathrm{Kg}^{-1}$} & \multicolumn{2}{|c|}{$\%$} \\
\hline 7,14 & 520 & 720 & 0,0 & 0,8 & 7,5 & 10,1 & 0 & 92 \\
\hline
\end{tabular}

Em cada recipiente foram semeadas três sementes, as quais foram recobertas com uma fina camada do mesmo substrato utilizado. Aproximadamente 20 dias após a semeadura foi realizado desbaste com o objetivo de eliminar as plantas jovens excedentes em cada recipiente, deixando-se apenas a muda mais vigorosa que se encontrava na posição central do saco plástico. Inicialmente as mudas permaneceram em casa de sombra coberto por malha preta com $50 \%$ de sombreamento, após 45 dias da semeadura as mudas foram transferidas para uma área de pleno sol.

A emergência e sobrevivência das plantas foram avaliadas semanalmente, aos 135 dias após a semeadura a altura das mudas foi mensurada a partir do nível do substrato até a última gema apical, utilizando-se uma régua milimétrica. Também foram avaliados os parâmetros morfológicos de desenvolvimento das mudas, sendo realizado a contagem do número de folhas e a medição do diâmetro do colo das mudas, obtido por meio de um paquímetro digital. Para a quantificação da massa seca, o sistema radicular foi separado da parte aérea e lavado em água corrente, utilizando peneira fina para evitar perda das raízes. Em seguida, a parte aérea e o sistema radicular das trinta plantas de cada repetição foram acondicionados separadamente em sacos de papel identificados, sendo posteriormente colocados em estufa de circulação de ar interna, a $60^{\circ} \mathrm{C}$. Foram avaliados: o peso da massa seca da parte aérea, peso da massa seca das raízes, peso da massa seca total e índices morfológicos: relação altura/diâmetro do coleto, peso da massa seca parte aérea/peso da matéria seca de raízes.

\section{Efeito do condicionamento sobre o armazenamento das sementes}

Para avaliar o efeito do condicionamento no armazenamento das sementes, foram avaliadas sementes com e sem condicionamento, armazenadas em geladeira a $10^{\circ} \mathrm{C}$ e em temperatura de $25^{\circ} \mathrm{C}$ em sala climatizada. Também foram testados diferentes recipientes de armazenamento, saco plástico e pote de vidro. Aos 30, 90 e 150 dias após o armazenamento as sementes foram analisadas através do teste de germinação e foi feito o cálculo do IVG. O experimento foi conduzido em delineamento inteiramente casualizado em esquema fatorial triplo ( 2 temperaturas: 10 e $25^{\circ} \mathrm{C} \times 2$ recipientes: saco plástico e pote de vidro $\times 2$ com e sem condicionamento), totalizando 8 tratamentos. A viabilidade das sementes foi avaliada pelo teste de germinação com quatro repetições contendo de 25 sementes.

\section{Análise estatística}

Os dados obtidos foram submetidos a teste de normalidade utilizando o teste 
de Kolmogorov-Smirnov, posteriormente realizou-se à análise de variância e quando significativo as médias foram comparadas pelo teste de Scott Knott a $5 \%$ de probabilidade, para evitar ambiguidade. Todas as análises foram realizadas com 0 auxílio do pacote computacional Assistat 6.0 (SILVA \& AZEVEDO, 2016).

\section{RESULTADOS E DISCUSSÃO}

\section{Efeito do condicionamento na qualidade fisiológica da semente}

Para a germinação das sementes nos diferentes tratamentos, não houve efeito significativo entre potencial, temperatura e tempo de embebição, porém houveram efeitos significativos entre potencial e temperatura. Pode-se observar que o potencial 0,0 (água pura) e $-0,4 \mathrm{Mpa}$ na temperatura de $15^{\circ} \mathrm{C}$ foram os tratamentos que apresentaram maior porcentagem de germinação (Tabela 2). Silva et al. (2005) estudando o efeito do estresse hídrico sobre a germinação de sementes de faveleira (Cnidoscolus juercifolius) verificaram inibição da germinação a medida que se aumenta o potencial hídrico, sendo que ocorreu inibição completa da germinação a partir de -0,9 Mpa.

TABELA 2. Germinação (\%) de sementes de $A$. mangium em diferentes tempos de embebição e temperaturas em função dos quatros potenciais hídricos. Urutaí, Goiás, 2014.

\begin{tabular}{cccccc}
\hline $\begin{array}{c}\text { Potencial } \\
\text { (MPa) }\end{array}$ & $\begin{array}{c}\text { Temperatura } \\
\left({ }^{\circ} \mathrm{C}\right)\end{array}$ & 28 & 36 & 44 & Média \\
\cline { 3 - 6 } 0 & 15 & $87( \pm 3,8) \mathrm{aA}$ & $86( \pm 5,2) \mathrm{aA}$ & $74( \pm 7,7) \mathrm{aA}$ & $82 \mathrm{a}$ \\
0,0 & 20 & $86( \pm 5,2) \mathrm{aA}$ & $86( \pm 6,9) \mathrm{aA}$ & $40( \pm 11,8) \mathrm{cB}$ & $70 \mathrm{~b}$ \\
& 25 & $83( \pm 8,9) \mathrm{aA}$ & $55( \pm 29,5) \mathrm{bB}$ & $2( \pm 2,0) \mathrm{eC}$ & $46 \mathrm{c}$ \\
\hline \multirow{3}{*}{0,1} & 15 & $77( \pm 6,0) \mathrm{bA}$ & $77( \pm 12,8) \mathrm{aA}$ & $57( \pm 13,6) \mathrm{bB}$ & $70 \mathrm{~b}$ \\
& 20 & $67( \pm 3,8) \mathrm{cB}$ & $41( \pm 10,0) \mathrm{cC}$ & $80( \pm 13,9) \mathrm{aA}$ & $63 \mathrm{~b}$ \\
& 25 & $72( \pm 18,8) \mathrm{bA}$ & $41( \pm 5,0) \mathrm{cC}$ & $62( \pm 5,2) \mathrm{bB}$ & $58 \mathrm{~b}$ \\
\hline \multirow{3}{*}{0,2} & 15 & $41( \pm 10,0) \mathrm{dA}$ & $54( \pm 7,7) \mathrm{bA}$ & $49( \pm 10,7) \mathrm{bA}$ & $48 \mathrm{c}$ \\
& 20 & $67( \pm 3,6) \mathrm{cB}$ & $90( \pm 2,3) \mathrm{aA}$ & $48( \pm 10,8) \mathrm{cC}$ & $68 \mathrm{~b}$ \\
& 25 & $79( \pm 25,6) \mathrm{bA}$ & $50( \pm 16,8) \mathrm{bB}$ & $20( \pm 15,7) \mathrm{dC}$ & $49 \mathrm{c}$ \\
\hline \multirow{3}{*}{0,4} & 15 & $90( \pm 12,4) \mathrm{aA}$ & $83( \pm 8,7) \mathrm{aA}$ & $90( \pm 7,7) \mathrm{aA}$ & $87 \mathrm{a}$ \\
& 20 & $27( \pm 39,6) \mathrm{eB}$ & $86( \pm 5,2) \mathrm{aA}$ & $72( \pm 9,8) \mathrm{bA}$ & $61 \mathrm{~b}$ \\
& 25 & $73( \pm 8,9) \mathrm{bB}$ & $73( \pm 6,0) \mathrm{aA}$ & $85( \pm 8,2) \mathrm{aA}$ & $77 \mathrm{~b}$ \\
\hline
\end{tabular}

Médias seguidas pela mesma letra, minúscula compara na coluna (vertical) e maiúscula compara na linha (horizontal), não diferem estatisticamente entre si pelo teste de Scott-Knott ao nível de $5 \%$ de probabilidade. CV: coeficiente de variação.

Para o IVG nos diferentes tratamentos, também não houve efeito significativo entre potencial, temperatura e tempo de embebição, porém houve efeitos significativos entre potencial e temperatura. Pode-se observar que o potencial 0,0 (água pura) na temperatura de 15 e $20^{\circ} \mathrm{C}$, o potencial $-0,2$ na temperatura de $20^{\circ} \mathrm{C}$ e $-0,4 \mathrm{Mpa}$ na temperatura de 15 e $25^{\circ} \mathrm{C}$ foram os tratamentos que apresentaram maior IVG (Tabela 3). 
TABELA 3. Índice de Velocidade de Germinação (IVG) de sementes de $A$. mangium Willd. em diferentes tempos de embebição e temperaturas em função dos quatros potenciais hídricos. Urutaí, Goiás, 2014.

\begin{tabular}{|c|c|c|c|c|c|}
\hline \multirow{2}{*}{$\begin{array}{c}\text { Potencial } \\
\text { (MPa) }\end{array}$} & \multirow{2}{*}{$\begin{array}{c}\text { Temperatura } \\
\left({ }^{\circ} \mathrm{C}\right)\end{array}$} & \multicolumn{3}{|c|}{ Tempo de embebição } & \multirow[b]{2}{*}{ Média } \\
\hline & & 28 & 36 & 44 & \\
\hline \multirow{3}{*}{0,0} & 15 & $37,3( \pm 1,6)$ aA & $30,5( \pm 2,2)$ aA & $13,7( \pm 2,7) \mathrm{cB}$ & $26,8 b$ \\
\hline & 20 & $36,5( \pm 2,2)$ aA & $37,0( \pm 3,1)$ aA & $7,2( \pm 2,6) \mathrm{dB}$ & $27,2 \mathrm{a}$ \\
\hline & 25 & $35,6( \pm 3,8)$ aA & $24,5( \pm 11,4) b B$ & $0,0( \pm 0,3) \mathrm{eC}$ & $20,1 b$ \\
\hline \multirow{3}{*}{$-0,1$} & 15 & $34,2( \pm 2,5)$ aA & $33,0( \pm 5,7)$ aA & $12,7( \pm 4,0) \mathrm{cB}$ & $26,7 b$ \\
\hline & 20 & $29,7( \pm 1,7) b A$ & $19,0( \pm 3,8) \mathrm{cB}$ & $24,7( \pm 6,2)$ aA & $24,5 b$ \\
\hline & 25 & $31,5(1,6)$ aA & $18,2( \pm 1,6) \mathrm{cB}$ & $11,5( \pm 1,5) \mathrm{dB}$ & $20,2 b$ \\
\hline \multirow{3}{*}{$-0,2$} & 15 & $19,0( \pm 3,8) \mathrm{cA}$ & $23,0( \pm 3,3) b A$ & $7,7( \pm 2,1) \mathrm{cB}$ & $16,7 \mathrm{c}$ \\
\hline & 20 & $31,7( \pm 3,7) b A$ & $38,2( \pm 1,2)$ aA & $16,2( \pm 4,7) b B$ & $28,9 a$ \\
\hline & 25 & $36,5( \pm 7,9)$ aA & $21,2( \pm 6,9) \mathrm{cB}$ & $3,4( \pm 2,2)$ eB & $20,6 b$ \\
\hline \multirow{4}{*}{$-0,4$} & 15 & $38,5( \pm 4,9)$ aA & $35,5( \pm 4,0)$ aA & $17,0( \pm 1,5) b B$ & $30,3 a$ \\
\hline & 20 & $21,2( \pm 12,1) \mathrm{cB}$ & $33,7( \pm 4,1)$ aA & $12,8( \pm 2,5) \mathrm{dC}$ & $22,5 b$ \\
\hline & 25 & $32,7( \pm 3,6)$ aA & $35,0( \pm 3,1)$ aA & $15,8( \pm 2,1) b B$ & $27,6 \mathrm{a}$ \\
\hline & CV (\%) & & 18,97 & & \\
\hline
\end{tabular}

Médias seguidas pela mesma letra, minúscula compara na coluna e maiúscula compara na linha, não diferem estatisticamente entre si pelo teste de Scott-Knott ao nível de $5 \%$ de probabilidade. CV: coeficiente de variação.

Com base nos resultados obtidos de germinação e IVG, observa-se que o tratamento $-0,4 \mathrm{MPa}$ na temperatura de $15^{\circ} \mathrm{C}$ no tempo de embebição de 28 e 36 horas se destacaram em relação aos demais tratamentos (Tabela 2 e 3 ), sendo assim em termos práticos pode-se indicar o tempo de embebição de 28 horas, para facilitar a execução do tratamento.

\section{Efeito do condicionamento na produção de mudas}

Pode-se observar que as mudas oriundas do condicionamento fisiológico das sementes demostraram comportamento semelhante às mudas sem condicionamento (Tabela 4). As variáveis referentes à emergência e sobrevivência das mudas não apresentaram diferença significativa em função do tratamento prégerminativo.

TABELA 4. Emergência das plântulas e sobrevivência das mudas $A$. mangium Willd. com e sem condicionamento osmótico, aos 135 dias após a semeadura. Urutaí, Goiás, 2014.

\begin{tabular}{ccc}
\hline Tratamentos & Emergência(\%) & Sobrevivência(\%) \\
\hline Sem condicionamento $^{*}$ & $93,33^{\mathrm{ns}}$ & $93,33^{\mathrm{ns}}$ \\
Com condicionamento $^{\mathrm{ns}}$ & 90,00 & 93,33 \\
\hline CV $(\%)$ & 30,61 & 27,18 \\
\hline
\end{tabular}

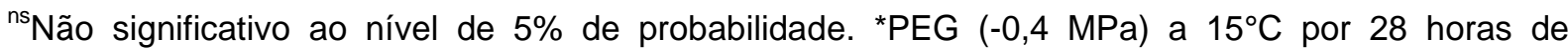
embebição. CV: coeficiente de variação.

Em relação ao desempenho das mudas de $A$. mangium também não foram observadas diferenças estatísticas significativas entre os tratamentos, os resultados referentes à altura da planta, diâmetro do colo, número de folhas e a relação entre a altura e o diâmetro não diferiram entre os tratamentos (Tabela 5). Isto indica que o condicionamento das sementes no potencial de $-0,4 \mathrm{Mpa}$ na temperatura de $15^{\circ} \mathrm{C}$ ENCICLOPÉDIA BIOSFERA, Centro Científico Conhecer - Goiânia, v. 15 n.27; p. 954 
durante 28 horas não foi eficiente para melhorar a qualidade das mudas, porém o condicionamento não prejudicou estas características.

TABELA 5. Valores médios de altura da parte aérea $(H)$, diâmetro do coleto (D), número de folhas e relação altura e diâmetro $(H / D)$ das mudas de $A$. mangium Willd. com e sem condicionamento osmótico, aos 135 dias após a semeadura. Urutaí, Goiás, 2014.

\begin{tabular}{ccccc}
\hline Condicionamento & $\mathrm{H}(\mathrm{cm})$ & $\mathrm{D}(\mathrm{mm})$ & $\mathrm{NF}$ & $\mathrm{H} / \mathrm{D}$ \\
\hline Sem condicionamento & $22,68^{\mathrm{ns}}$ & $3,86^{\mathrm{ns}}$ & $9,93^{\mathrm{ns}}$ & $5,86^{\mathrm{ns}}$ \\
Com condicionamento* $^{*}$ & 23,34 & 3,73 & 8,08 & 6,23 \\
\hline CV $(\%)$ & 24,87 & 17,66 & 40,05 & 15,55 \\
\hline
\end{tabular}

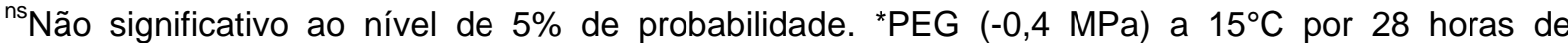
embebição. CV: coeficiente de variação.

A massa seca da parte aérea (MSA) e da raiz (MSR) bem como a massa seca total (MST) não apresentaram diferenças significativas (Tabela 6). No entanto, a relação da MSA/MSR apresentou diferença significativa entre os tratamentos, sendo que o tratamento com condicionamento demonstrou superioridade sobre as mudas que não foram previamente condicionadas, pois valores inferiores para esta relação é desejável, neste caso quanto menor relação, maior o equilíbrio na produção de matéria seca. Assim, na produção de mudas o condicionamento osmótico avaliado (-0,4 MPA a $15^{\circ} \mathrm{C}$ durante 28 horas) foi eficiente apenas para diminuir a relação MSA/MSR, no entanto esta técnica não prejudicou as demais características observadas na produção de mudas.

TABELA 6. Massa seca da parte áerea (MSA), da raiz (MSR), massa seca total (MST) e relação massa seca da parte aérea e raiz (MSA/MSR) das mudas de $A$. mangium Willd. com e sem condicionamento osmótico, aos 135 dias após a semeadura. Urutaí, Goiás, 2014.

\begin{tabular}{ccccc}
\hline Condicionamento & MSA $(\mathrm{g})^{\mathrm{ns}}$ & $\mathrm{MSR}(\mathrm{g})^{\mathrm{ns}}$ & $\mathrm{MST}(\mathrm{g})^{\mathrm{ns}}$ & MAS/MSR $^{*}$ \\
\hline Sem condicionamento & 3,28 & 1,38 & $4,67^{\mathrm{ns}}$ & $2,44 \mathrm{a}$ \\
Com condicionamento $^{* *}$ & 3,01 & 1,52 & 4,54 & $2,03 \mathrm{~b}$ \\
\hline CV $(\%)$ & 38,30 & 37,87 & 36,95 & 23,61 \\
\hline
\end{tabular}

${ }^{\text {ns }}$ Não significativo e *Significativo a $5 \%$ de probabilidade pelo teste de médias. **PEG (-0,4 MPa) a $15^{\circ} \mathrm{C}$ por 28 horas de embebição. ${ }^{* * *}$ MAS: Massa seca da parte aérea; MSR: massa seca da raiz; MST: Massa seca total. CV: coeficiente de variação.

Batista et al. (2015), estudando sementes de pimenteira hidrocondicionadas, constataram que o condicionamento fisiológico propiciou maior velocidade de emergência, e que as sementes condicionadas produziram mudas com maior fitomassa seca.

A pré-hidratação de sementes de maracujá-amarelo (Passiflora edullis) com água aquecida a $40{ }^{\circ} \mathrm{C}$ por 20 minutos combinada à imersão em PEG 6000 por $36 \mathrm{~h}$ resultou em maior uniformidade de plântulas e $90 \%$ de germinação (ARAÚJO et al., 2017). Já para sementes de E. grandis não é recomendado o uso de solução de nitrato de potássio a $0,2 \%$ no substrato de germinação, no potencial osmótico da semente, todavia o uso dessa solução no teste de germinação possibilita maior percentual de germinação, porém com menor velocidade (SILVA et al., 2017). Também para Chorisia glaziovii o condicionamento não foi eficiente, sendo as 
sementes sensíveis ao estresse hídrico, com germinação totalmente inibida no potencial de -0,3 MPa (SILVA et al, 2016)

\section{Efeito do condicionamento no armazenamento das sementes}

Para a germinação e IVG após o armazenamento, pode-se observar que aos 30 dias após o armazenamento não houve efeito significativo entre a interação condicionamento, temperatura e recipiente. Também não verificou-se interação significativa entre condicionamento e temperatura (Tabela 7). Neste caso, o pouco tempo de armazenamento pode ter contribuído para os resultados. Assim para o tempo de 30 dias de armazenamento o condicionamento não interferiu na germinação e IVG das sementes.

TABELA 7. Germinação (\%) e índice de velocidade de germinação (IVG) para sementes de $A$. mangium armazenadas durante 30 dias após diferentes tratamentos. Com condicionamento (C.C.) e sem condicionamento (S.C.); em temperatura de 10 e $25^{\circ} \mathrm{C}$; em sacos plásticos e pote de vidro. Urutaí, Goiás, 2014.

\begin{tabular}{llllllll}
\hline Temperatura & Recipiente & \multicolumn{3}{c}{ Germinação (\%) } & \multicolumn{3}{c}{ IVG } \\
\cline { 3 - 7 } & & CC $^{\text {ns }}$ & SC $^{\text {ns }}$ & Média $^{\text {ns }}$ & CC $^{\text {ns }}$ & SC $^{\text {ns }}$ & Média $^{\text {ns }}$ \\
\hline $10^{\circ} \mathrm{C}$ & Plástico & 74 & 74 & 74 & 26 & 27 & 26 \\
& Vidro & 79 & 87 & 83 & 28 & 28 & 28 \\
\hline $25^{\circ} \mathrm{C}$ & Plástico & 77 & 79 & 78 & 20 & 28 & 24 \\
& Vidro & 78 & 86 & 82 & 30 & 29 & 29 \\
\hline Média $^{\text {ns }}$ & & 77 & 81 & 79 & 26 & 28 & 27
\end{tabular}

${ }^{\text {ns }}$ Não significativo e *Significativo a $5 \%$ de probabilidade pelo teste de médias.

Também aos 90 dias após o armazenamento não houve efeito significativo entre a interação condicionamento, temperatura e recipiente, para germinação e IVG. Porém quando avalia a germinação com e sem condicionamento, observa-se que o condicionamento favoreceu a germinação das sementes (Tabela 8). Para o IVG houve interação significativa entre a temperatura e recipiente, sendo as sementes condicionadas armazenadas em saco plástico na temperatura de $10^{\circ} \mathrm{C}$ as que apresentaram maior IVG.

TABELA 8. Germinação (\%) e índice de velocidade de germinação (IVG) para sementes de $A$. mangium armazenadas durante 90 dias após diferentes tratamentos. Com condicionamento (C.C.) e sem condicionamento (S.C.); em temperatura de 10 e $25^{\circ} \mathrm{C}$; em sacos plásticos e pote de vidro. Urutaí, Goiás, 2014.

\begin{tabular}{|c|c|c|c|c|c|c|c|}
\hline \multirow[t]{2}{*}{ Temperatura } & \multirow[t]{2}{*}{ Recipiente } & \multicolumn{3}{|c|}{ Germinação (\%) } & \multicolumn{3}{|c|}{ IVG } \\
\hline & & CC & SC & Média ns & $\mathrm{CC}$ & SC & Média \\
\hline \multirow[t]{2}{*}{$10^{\circ} \mathrm{C}$} & Plástico & $86 a A$ & $65 a B$ & 75 & $12,2 a A$ & $9,1 \mathrm{aB}$ & $10,6 a$ \\
\hline & Vidro & $64 \mathrm{bA}$ & $74 a A$ & 69 & $7,5 \mathrm{bA}$ & $7,7 a A$ & $7,6 b$ \\
\hline \multirow[t]{2}{*}{$25^{\circ} \mathrm{C}$} & Plástico & $80 a A$ & $73 a A$ & 76 & $8,7 \mathrm{bA}$ & $8,3 a A$ & $8,5 b$ \\
\hline & Vidro & $92 \mathrm{aA}$ & $58 \mathrm{bB}$ & 75 & $9,6 \mathrm{bA}$ & $9,2 \mathrm{aA}$ & $9,4 b$ \\
\hline Média & & $80,5 \mathrm{~A}$ & $67,5 \mathrm{~B}$ & 74 & $9,5 \mathrm{~A}$ & $8,5^{\mathrm{a}}$ & 9,0 \\
\hline
\end{tabular}

Letras maiúsculas comparam nas coluna, letras minúsculas nas linhas. Teste: ScottKnott a $5 \%$. 
Aos 150 dias após o armazenamento também não houve efeito significativo entre a interação condicionamento, temperatura e recipiente, para germinação e IVG. Porém quando avalia a germinação com e sem condicionamento, observa-se que o condicionamento influenciou negativamente na germinação e IVG das sementes (Tabela 8). Quando avalia recipiente e temperatura observa-se que para as sementes condicionadas a temperatura de $10^{\circ} \mathrm{C}$ em sacos plásticos foi a que apresentou melhores resultados de germinação.

TABELA 9. Germinação (\%) e índice de velocidade de germinação (IVG) para sementes de $A$. mangium armazenadas durante 90 dias após diferentes tratamentos. Com condicionamento (C.C.) e sem condicionamento (S.C.); em temperatura de 10 e $25^{\circ} \mathrm{C}$; em sacos plásticos e pote de vidro. Urutaí, Goiás, 2014.

\begin{tabular}{|c|c|c|c|c|c|c|c|}
\hline \multirow[t]{2}{*}{ Temperatura } & \multirow[t]{2}{*}{ Recipiente } & \multicolumn{3}{|c|}{ Germinação (\%) } & \multicolumn{3}{|c|}{ IVG } \\
\hline & & $\mathrm{CC}$ & SC & Média & CC & SC & Média \\
\hline \multirow[t]{2}{*}{$10^{\circ} \mathrm{C}$} & Plástico & $53 a B$ & $88 a A$ & $70 a$ & $0,9 a B$ & $31,6 a A$ & $16,2 a$ \\
\hline & Vidro & $9 \mathrm{bB}$ & $73 a A$ & $41 b$ & $1,5 \mathrm{aB}$ & $24,5 \mathrm{bA}$ & $13,0 \mathrm{a}$ \\
\hline \multirow[t]{2}{*}{$25^{\circ} \mathrm{C}$} & Plástico & $12 \mathrm{bB}$ & $84 a A$ & $48 b$ & $1,6 \mathrm{aB}$ & $31,0 a A$ & $16,3 a$ \\
\hline & Vidro & $0,3 \mathrm{cB}$ & $82 \mathrm{aA}$ & $42 b$ & $01 \mathrm{aB}$ & $30,0 a A$ & $15,0 a$ \\
\hline Média & & $19 \mathrm{~B}$ & $82 \mathrm{~A}$ & 50,5 & $1,0 \mathrm{~B}$ & $29,7 \mathrm{~A}$ & 15,1 \\
\hline
\end{tabular}

Letras maiúsculas comparam nas colunas, letras minúsculas nas linhas. Teste: Scott-

Knott a $5 \%$.

Sendo assim, o armazenamento das sementes após o condicionamento pode ser realizado até os 60 dias, sem que a semente perca sua capacidade germinativa, o prolongamento deste período de armazenamento provoca redução da germinação e IVG das sementes. O armazenamento por 150, após o condicionamento das sementes, deve ser realizado em temperatura de $10^{\circ} \mathrm{C}$ em recipientes plásticos, para que possa manter uma porcentagem de germinação próxima aos $50 \%$.

\section{CONCLUSÃO}

O condicionamento fisiológico influenciou o desempenho germinativo das sementes de $A$. mangium, sendo que o potencial hídrico de -0,4 $\mathrm{MPa}$ demonstrou ser o mais eficiente para aumentar a germinação e o IVG.

$\mathrm{Na}$ produção de mudas o efeito do condicionamento mostrou-se eficiente apenas para reduzir a relação de massa seca da parte aérea/massa seca da raiz, não influenciando nos demais parâmetros morfológicos de qualidade das mudas.

O condicionamento de sementes de $A$. mangium seguido de armazenamento é considerado viável até os 60 dias após o armazenamento, ampliando e facilitando as possibilidades de produção de mudas das sementes.

\section{REFERÊNCIAS}

ARAUJO, M. M. V.; FERNANDES, D. A.; JARDINI, D. C.; CAMILI, E. C. Préhidratação e condicionamento fisiológico de sementes de maracujazeiro amarelo. Revista AgroOmbiente On-line, v. 11, n. 3, p. 241-247, julho-setembro, 2017. Disponível em: < http://dx.doi.org/10.18227/1982-8470ragro.v11i3.3645>. Doi: $0.18227 / 1982-8470$.

BATISTA, T. B.; BINOTTI, F. F. S.; CARDOSO, E. D.; B. ARDIVIESSO, E. M.; COSTA, E. Aspectos fisiológicos e qualidade de mudas da pimenteira em resposta 
ao vigor e condicionamento das sementes. Bragantia, Campinas, v.74, n. 4, p. 367373, 2015. Disponível em: <http://dx.doi.org/10.1590/1678-4499.0133>. Doi: $10.1590 / 1678-4499.0133$

GUEDES, R. S.; ALVES, E. U.; SANTOS-MOURA, S. S.; COSTA, E. G.; MELO, P. A. F. R. Tratamentos para superar dormência de sementes de Cassia fistula L. Revista Biotemas, v. 26, n. 4, p. 11-22, dezembro de 2013. Disponível em: <http://dx.doi.org/10.5007/2175-7925.2013v26n4p11> doi: 10.5007/2175.

INMET - Instituto Nacional de Meteorologia . Disponível em: http://www.inmet.gov.br. Acessado em: 23 de nov de 2015.

MASETTO, T. E.; FARIA, J. M. R.; FRAIZ, A. C. R.; REZENDE, R. K. S. Condicionamento osmótico de sementes de Sesbania virgata (CAV.) PERS (Fabaceae). Cerne, Lavras, v. 19, n. 4, p. 629-636, out./dez. 2013. Disponível em: <http://dx.doi.org/10.1590/S0104-7602013000400013> doi: 10.1590/S0104$7602013000400013 a$

MICHEL, B. E.; KAUFMANN, M. R. The osmotic potential of polyethylene glycol 6000. Plant Physiology, Minneapolis, v. 51, n. 5, p. 914-916, mai. 1973. Disponível em: < https://doi.org/10.1104/pp.51.5.914> doi: 10.1104

MORAIS, C. S. B.; ALMEIDA, L. G.; SANTOS, M. B.; ROSSETTO, C. A. V. Resposta de plantas ao condicionamento osmótico de sementes de girassol. Ciências Agrárias, Londrina, v. 35, n. 5, p. 2261-2274, set./out. 2014. Disponível em: <https://doi.org/105433/1679-0359.2014> doi: 105433/1679

POWEL, A. A.; YULE, L. J.; JUNG, H. C.; GROOT, P. C. The influence of aerated hydration seed treatment on seed longevity as assessed by the viability equation. Journal Experimental Botany, Oxford, v. 51, n. 353, p. 2031-2043, dec. 2000. Disponível em: <https://doi.org/10.1093/jexbot/51.353.2031> doi: 10.1093

SILVA, A. G.; PAULA, R. C. M.; BINOTTI.; COSTA, E. Comportamento germinativo de sementes de eucalipto em duas temperaturas com o uso de sais inorgânicos. Enciclopédia biosfera, Centro Científico Conhecer - Goiânia, v.14 n.25; p.358-365, 2017. Disponóivel em:<http://10.18677/EnciBio_2017A33> doi: 10.18677

SILVA, F. de A. S.; AZEVEDO, C. A. V. de. The Assistat Software Version 7.7 and its use in the analysis of experimental data. Afr. J. Agric. Res, v.11, n.39, p.3733-3740, 2016. Disponível em: <http://dx.doi.org/10.5897/AJAR2016.11522> doi: 10.5897/AJAR2016.11522

SILVA, L. M. M.; AGUIAR, I. B.; MORAIS, R. A. VIÉGAS. Estresse hídrico e condicionamento osmótico na qualidade fisiológica de sementes de Cnidoscolus juercifolius. Revista Brasileira de Engenharia Agrícola e Ambiental, Campina Grande, v. 9, n. 1, p. 66-72, jan./mar. 2005. Disponível em: <http://dx.doi.org/10.1590> doi: http://10.1590

SILVA, M. L. M.; ALVES, E. U.; BRUNO, R. L. A.; SANTOS-MOURA, S. S.; SANTOS 
NETO, A. P. Germinação de sementes de Chorisiaglaziovii Kuntze submetidas ao estresse hídrico em diferentes temperaturas. Ciência Florestal, Santa Maria, v. 26, n. 3, p. 999-1007, 2016. Disponível em: <http://dx.doi.org/10.5902/1980509824229>. doi: $10.5902 / 1980509824229$

SMIRDELE, O. J.; MOURÃO JÚNIOR, M.; SOUSA, R. C. P. Tratamentos prégerminativos em sementes de acácia. Revista Brasileira de Sementes, Londrina, v. 27, n. 1, p. 78-85, jan./mar. 2005. Disponível em: <http://dx.doi.org/10.1590/S010131222005000100010> doi: 10.1590/S0101-31222005000100010 